\title{
Corrosion Inhibitive Effect of 2-(1-(2-Oxo-2H-Chromen-3-Yl) Ethylidene) Hydrazine Carboxamide on Zinc-Aluminum Alloy in 1.8M Hydrochloric Acid
}

\author{
Aladesuyi O. ${ }^{1}$, Fatile B.O. ${ }^{2}$, Adedapo E.A. ${ }^{1}$, Ogunboyejo A.P. ${ }^{1}$, Ajanaku C.O. ${ }^{1}$, \\ Olanrewaju I. O. ${ }^{1}$, Ajani O.O. ${ }^{1}$, Ajanaku K.O. ${ }^{{ }^{*}}$ \\ ${ }^{1}$ Department of Chemistry, College of Science \& Technology, Covenant University, Ota, Ogun State \\ ${ }^{2}$ Department of Glass and Ceramics, Federal Polytechnic, Ado-Ekiti, Ekiti State \\ kola.ajanaku@covenantuniversity.edu.ng
}

\begin{abstract}
The corrosion inhibition of Zinc-Aluminum alloy in 1.8 M of hydrochloric acid solution by 2-(1-(2oxo-2H-chromen-3-yl) ethylidene) hydrazine carboxamide was carried out using weight loss method. ZincAluminum coupons were immersed in test solution of blank and solutions of $0.001 \mathrm{M}, 0.002 \mathrm{M}, 0.003 \mathrm{M}$ and $0.004 \mathrm{M}$ of the inhibitor at room temperature and $50^{\circ} \mathrm{C}$ consistently for seven days duration. The percentage inhibition efficiency (\% I.E) and surface coverage ( $\theta)$ of the Zinc-Aluminum was calculated and result indicated corresponding increase with concentration of inhibitor. The adsorption isotherm of the process was estimated using four adsorption isotherm theories namely: Langmuir, Freundlich, Temkin and Frumkin. The adsorption studies revealed that Langmuir isotherm $\left(R^{2}=0.9997\right)$ is the best model for the adsorption of 2-(1-(2-oxo-2Hchromen-3-yl) ethylidene) at room temperature and at $50^{\circ} \mathrm{C}$ on Zinc-Aluminum surface.
\end{abstract}

Keywords: Adsorption, Surface coverage, Inhibition efficiency, Isotherms, Zn/Al alloy.

\section{INTRODUCTION}

Corrosion is basically the destructive attack of metal by chemical or electrochemical reaction with its environment [1]; [2]; [3]; [4]; [5]; [6]. Deterioration process is initiated whenever there are chemical exposures that reverse the metal back to its original state [7]. Nonferrous metals corrode to get back to their original state just as water flows to the lowest level, all natural processes tends towards the lowest possible energy states [1]; [3]. Compared to aluminum, the zinc alloys are harder and stronger, machine more easily, have superior pressure tightness, and have substantially better wear and bearing characteristics [8]. However, studies have shown that $\mathrm{Zn} / \mathrm{Al}$ alloy resistance to corrosion decreases under aggressive environment [9].

The use of organic inhibitors has generated much interest in recent times in the field of prevention of corrosion and its control [10]. An inhibitor is a substance which, when added in small quantities to a corrosive medium that brings about an appreciable reduction of the corrosive action. The selection of suitable inhibitor depends on the type of acid, its concentration, temperature, flow velocity, the presence of dissolved inorganic or organic substance and type of metallic material exposed to the acid solution [7]. Heterocyclic compounds are usually indicated as counterparts of carbocyclic compounds, which have only ring atoms from the same element. They are class of organic compounds whose molecules contain one or more rings of atoms with at least one atom (the heteroatom) being an element other than carbon, most frequently oxygen, nitrogen, or sulphur. In addition, compounds with multiple bonds behave as efficient inhibitors due to the availability of p-electrons for interaction with the metal surface. $N$-heterocyclic compounds are well qualified to play more protection for steel corrosion. The heterocyclic compound containing nitrogen atoms can easily be protonated in acidic medium to exhibit good inhibitory action on the corrosion of metals in acid solutions [4]. Studies have shown that heterocyclic compounds are good inhibitor on the corrosion of metals in acidic solution [4]; [5]; [11]. In line with the reason above, the inhibitory properties of 2-(1-(2-oxo-2H-chromen-3-yl) ethylidene) hydrazine carboxamide on $\mathrm{Zn} / \mathrm{Al}$ metal in $1.8 \mathrm{M} \mathrm{HCl}$ at $278-323 \mathrm{~K}$ was studied by weight loss method. 


\section{MATERiAls AND MethodS}

\subsection{Synthesis of 2-(1-(2-Oxo-2H-Chromen-3-Yl) Ethylidene) Hydrazine Carboxamide}

The synthesis of 3-acetyl coumarin was done using ethyl acetoacetate and salicyaldehyde in the presence of a catalyst to create an active center. To ethyl acetoacetate $(11.5 \mathrm{ml}, 90.13 \mathrm{mmol})$ in catalytic amount of piperidine $(0.2 \mathrm{ml}, 1.64 \mathrm{mmol})$, was added salicyaldehyde $(8.6 \mathrm{ml}, 81.89 \mathrm{mmol})$ and heated under reflux for 20 min to afford a crude yellow solid (TLC monitored). The crude solid was recrystallized from methanol and cooled to obtain a solid which was filtered by suction and dried to afford yellow crystal of 3-acetylcoumarin, $(15.48 \mathrm{~g}, 99.6 \%)$. The reaction scheme is shown below:

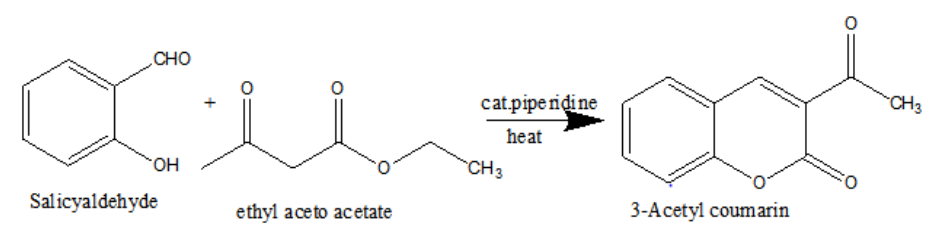

Scheme1. Synthesis of 3-acetyl coumarin from ethyl acetoacetate and salicyaldehyde

Then, 3-Acetylcoumarin (1.01g, $5.4 \mathrm{mmol}$ was dissolved in $100 \mathrm{ml}$ of ethanol followed by addition of semicarbazide hydrochloride $(0.604 \mathrm{~g}, 5.43 \mathrm{mmol})$. This was stirred at room temperature for 10 minutes after which the resulting mixture was refluxed at $80^{\circ} \mathrm{C}$ for 1 hour. This was allowed to cool overnight to form solid which was recrystallized from ethanol to achieve the required product which is 2-(1-(2-oxo-2H-chromen-3-yl) ethylidene) hydrazine carboxamide. The reaction scheme is shown below:

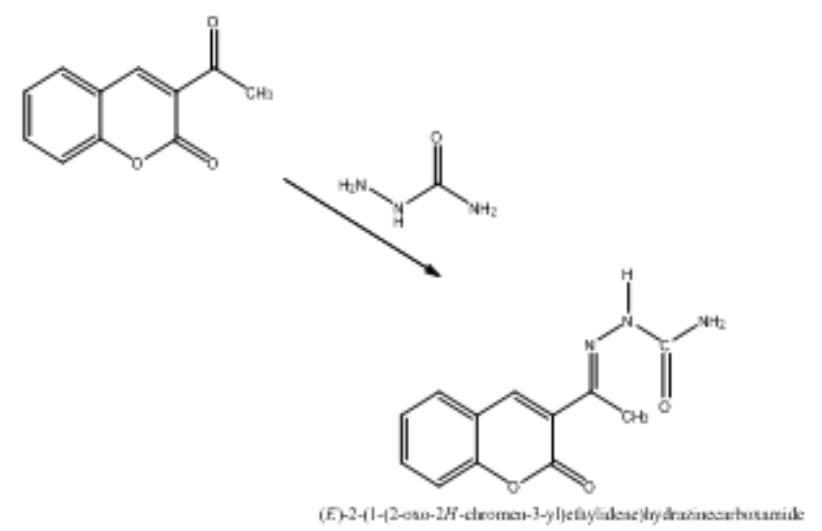

Scheme2. Synthesis of (2-(1-(2-oxo-2H-chromen-3-yl) ethylidene) hydrazine carboxamide from 3Acetylcoumarin and semicarbazide hydrochloride

\subsection{Weight Loss Measurement}

The Zinc-Aluminum alloy coupons of size $30 \mathrm{~mm}$ x $20 \mathrm{~mm}$ and $15 \mathrm{~mm}$ thickness were mechanically processed and washed thoroughly with ethanol, degreased with acetone and finally dried and weighed. The alloys were immersed in $100 \mathrm{ml}$ containing the blank solution and inhibitor concentrations of $0.001 \mathrm{M}, 0.002 \mathrm{M}, 0.003 \mathrm{M}$ and $0.004 \mathrm{M}$. After $24 \mathrm{hrs}$ interval the specimen was removed from the beaker and first washed with washing agent (zinc dust and sodium hydroxide pellet) and water then dropped in acetone to stop the effect of the concentrated $\mathrm{HCl}$, and was then weighed accurately with a weighing balance to determine its new weight. The corrosion rate (W) and the inhibition efficiency I.E (\%) were calculated using equations 1 and 2 [12]:

$W=\frac{W L}{A X T}$

I. $E(\%)=\frac{\Delta \text { W0- } \Delta \text { Winh }}{\Delta W_{0}} X 100$

Where $\mathrm{W}_{\mathrm{L}}$ is the difference between the initial weight and the final weight after the coupon has been immersed in the above solutions, $\mathrm{A}$ is the surface area of the alloy and $\mathrm{T}$ is the time of immersion. $\Delta \mathrm{W}_{\mathrm{o}}$ is the change in weight without the inhibitor and $\Delta \mathrm{W}_{\text {inh }}$ is the change in weight with the inhibitor.

The inhibitor efficiency depends on the degree of coverage of the zinc-aluminum alloy surface by the molecules of the inhibitor and can be expressed as in equation 3 : 
$\theta=\frac{\Delta W_{0}-\Delta \text { Winh }}{\Delta W_{0}}$

Where $\theta$ is the surface coverage

\subsection{Adsorption Studies}

The mechanism for corrosion inhibitor using organic compound is the adsorption of the inhibitor on the metal or alloy surface which obstruct the active sites and prevent corrosion of the metal or alloy from occurring. Adsorption studies provide the information about the interaction among the adsorbed molecules as well as with their metal or alloy surface [13]. There are two main types of interaction that can be used to explain the adsorption of organic compounds namely physisorption and chemisorption. These types are dependent on the electronic structure of the metal or alloy, nature of electrolyte, and the chemical structure of the inhibitor. It has been investigated that adsorption isotherms helps to understand the mechanism of heterogeneous organo-electrochemical reactions [14] involving surfaces. In adsorption isotherm studies, the degree of surface coverage $(\theta)$ is very important. The degree of surface coverage values for 2-(1-(2-oxo-2H-chromen-3-yl) ethylidene) hydrazine carboxamide was obtained from the weight loss measurement using equation - 3 . The Langmuir, Freundlich, Temkin and Frumkin isotherms were used to determine the best fitted correlation coefficient $\left(\mathrm{R}^{2}\right)$.

\section{RESUlTS AND DisCUSSION}

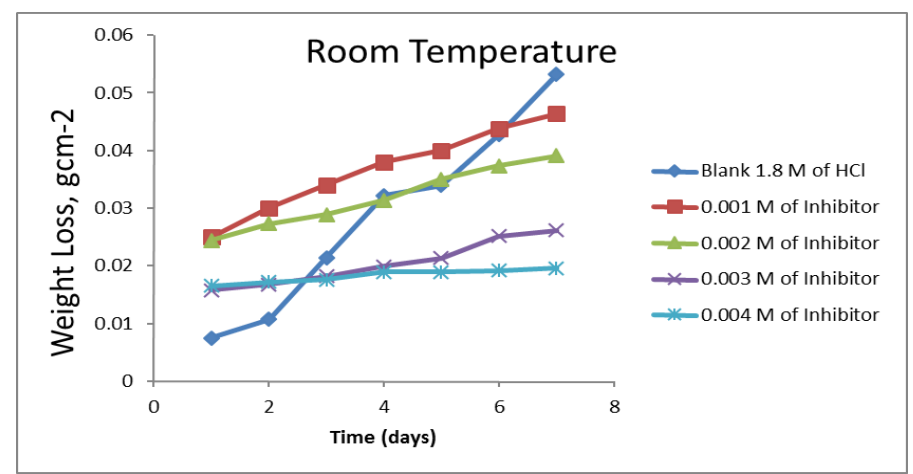

Figure1. Graph of $W_{L} / A$ against $T$ (days) at room temperature for each day of varying concentrations of 2-(1(2-oxo-2H-chromen-3-yl) ethylidene) hydrazine carboxamide in $1.8 \mathrm{M} \mathrm{of} \mathrm{HCl}$

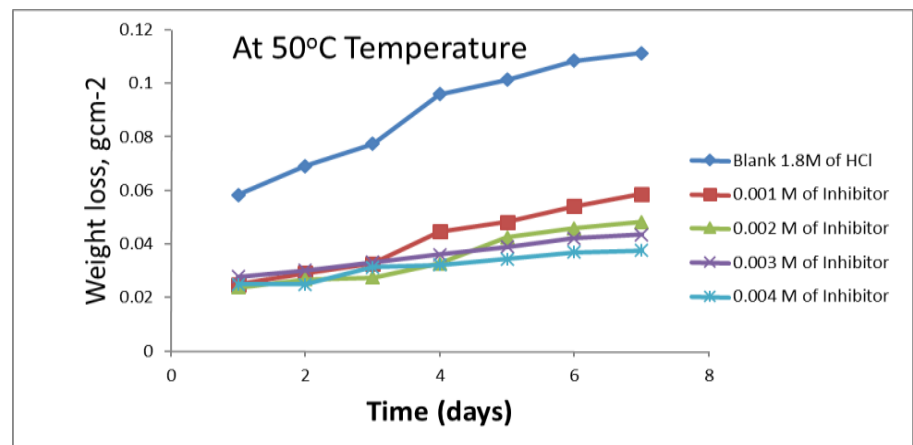

Figure2. Graph of $W_{L} / A$ against $T$ (days) at $50^{\circ} \mathrm{C}$ for each day of varying concentrations 2-(1-(2-oxo-2Hchromen-3-yl) ethylidene) hydrazine carboxamide in $1.8 \mathrm{M}$ of $\mathrm{HCl}$

\subsection{Corrosion Rate of 2-(1-(2-Oxo-2H-Chromen-3-Yl) Ethylidene) Hydrazine Carboxamide on Zn/A Alloy}

Figures 1 and 2 show the plot of corrosion rate against time for 2-(1-(2-oxo-2H-chromen-3-yl) ethylidene) hydrazine carboxamide at both room temperature and $50^{\circ} \mathrm{C}$ respectively. The results showed the rate of corrosion decreasing in the presence of 2-(1-(2-oxo- $2 \mathrm{H}$-chromen-3-yl) ethylidene $)$ hydrazine carboxamide with increasing concentration. The $0.004 \mathrm{M}$ of the inhibitor at the room temperature and $50^{\circ} \mathrm{C}$ has lowest corrosion rate with an indication that the inhibitory effect of the heterocyclic compound is concentration dependent. It was also observed that there is huge difference between the unhibited and the inhibited categories, which correlate well with other researches carried out in other media [15]; [16]; [17]. 


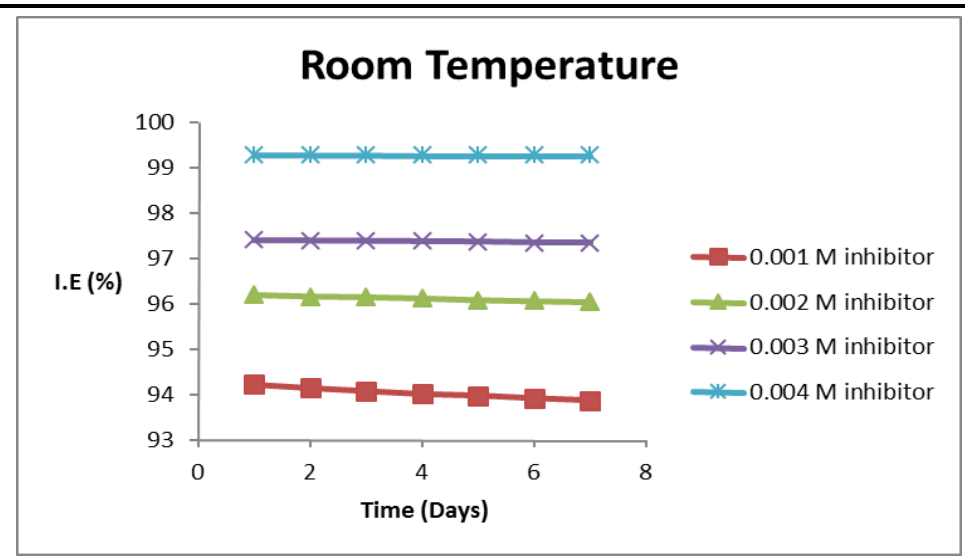

Figure3. Graph of inhibition efficiency of zinc-aluminum alloy against time (days) at room temperature for each day of varying concentration of 2-(1-(2-oxo-2H-chromen-3-yl) ethylidene) hydrazine carboxamide in 1.8 $\mathrm{M}$ of $\mathrm{HCl}$

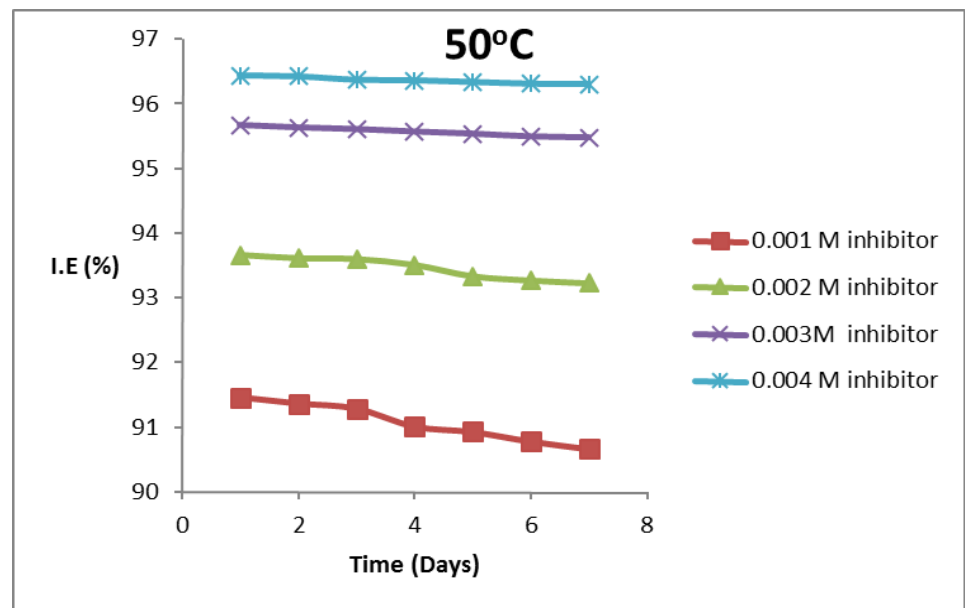

Figure4. Graph of inhibition efficiency of zinc-aluminum alloy against time (days) at $50^{\circ} \mathrm{C}$ temperature for each day of varying concentration of 2-(1-(2-oxo-2H-chromen-3-yl) ethylidene) hydrazine carboxamide in $1.8 \mathrm{M}$ of $\mathrm{HCl}$

\subsection{Inhibitor Efficiency Dependence on Inhibitor Concentration}

Figures 3 and 4 is the graphical representation of the inhibitor efficiency of 2-(1-(2-oxo-2H-chromen3 -yl) ethylidene) hydrazine carboxamide on the corrosion of $\mathrm{Zn} / \mathrm{Al}$ alloy at room temperature and 1.8 $\mathrm{M} \mathrm{HCl}$. It shows that inhibition efficiency increases with increasing concentration. The $0.004 \mathrm{M}$ of the inhibitor at the room temperature and $50^{\circ} \mathrm{C}$ possess the highest inhibitor efficiency. It was also observed the inhibitory strength of the inhibitor reduces at $50^{\circ} \mathrm{C}$ when compared to what was observed at room temperature. This is an indication that the inhibitory action of the heterocyclic compound is both concentration and temperature dependent.

\subsection{Adsorption Isotherms of Corrosion of $\mathrm{Zn}-\mathrm{Al}$ in $1.8 \mathrm{M} \mathrm{of} \mathrm{HCl}$}

The correlation coefficients of all the four isotherms studied at room temperature and at $50^{\circ} \mathrm{C}$ respectively are shown in the Table 1 . The correlation coefficient values increased in respect with temperature increase for all the adsorption isotherms. The $\mathrm{R}^{2}$ values at the two temperatures showed that the adsorption of 2-(1-(2-oxo-2H-chromen-3-yl) ethylidene) hydrazine carboxamide onto ZincAluminum alloy surface obeys Langmuir isotherm. The Langmuir isotherm characterizes chemisorption of the adsorbed species and postulated monolayer adsorption of the adsorbate unto the adsorbent which is expected to have a slope of unity. This was clearly established in the work. The slope of almost unity was observed in this experiment which is an indication that the heterocyclic compound is approximated by Langmuir adsorption isotherm and that the monolayer of the inhibitor species must have been attached to Zinc-Aluminum surface without lateral interaction between adsorbed species [18]. It was also observed that an increase in temperature, increases the uniformity of the molecules of the compound. 
Corrosion Inhibitive Effect of 2-(1-(2-Oxo-2H-Chromen-3-Yl) Ethylidene) Hydrazine Carboxamide on Zinc-Aluminum Alloy in 1.8M Hydrochloric Acid

Table1. Correlation coefficient of different adsorption isotherm of 2-(1-(2-oxo-2H-chromen-3-yl) ethylidene) hydrazine carboxamide at room temperature and at $50^{\circ} \mathrm{C}$

\begin{tabular}{|l|l|l|}
\hline \multicolumn{1}{|c|}{ Adsorption Isotherm } & \multicolumn{1}{c|}{$\mathbf{R}^{\mathbf{2}}$ (Room Temperature) } & \multicolumn{1}{c|}{$\left.\mathbf{R}^{\mathbf{2}} \mathbf{5 0}^{\mathbf{0}} \mathbf{C}\right)$} \\
\hline Langmuir & 0.9898 & 0.9997 \\
\hline Freundlich & 0.7419 & 0.9928 \\
\hline Temkin & 0.9431 & 0.9975 \\
\hline Frumkin & 0.9104 & 0.9817 \\
\hline
\end{tabular}

\section{CONClusion}

The synthesized heterocyclic compound (2-(1-(2-oxo-2H-chromen-3-yl) ethylidene) hydrazine carboxamide) acts as potential inhibitor for Zinc-Aluminum corrosion in $1.8 \mathrm{M} \mathrm{HCl}$ medium. The corrosion inhibitive efficiency of the heterocyclic compound increased with increase in concentration of the compound which indicated that the inhibitive action is concentration dependent. The highest inhibition concentration was observed at $0.004 \mathrm{M}$ of 2-(1-(2-oxo-2H-chromen-3-yl) ethylidene) hydrazine carboxamide. The corrosion inhibition efficiency was temperature dependent. The heterocyclic compound was found to obey Langmuir adsorption isotherm from the fit of the experimental data in all concentrations studied implying that adsorption is chemisorption.

\section{REFERENCES}

[1] Abdulwali, N., Ennajih, H., Guenbour, A., Bellaouchou, A., Al-subari, R., Anton, G.J and Essassi, E. Inhibition of mild steel corrosion in $1 \mathrm{M}$ hydrochloric acid by benzimidazolium bromide derivatives. Australian Journal of basic and Applied Science, (2013), 7(6), 1-8.

[2] Ajanaku, K.O., Aladesuyi, O., Anake W.U., Edobor-Osoh, A., Ajanaku, C.O. and Siyanbola, T.O. Inhibitive properties of carica papaya leaf extract on Aluminum in $1.85 \mathrm{M} \mathrm{HCl}$. Journal for Advances in Chemistry, (2014), 8(2), 1651-1659.

[3] Ghazoui, A., Saddik, R., Benchat, N., Hammouti, B., Guenbour, M., Zarrouk, A. and Ramdani, M. The Role of 3-Amino-2-Phenylimidazo [1, 2-a] Pyridine as Corrosion Inhibitor for C38 Steel in 1M HCl. Der Pharma Chemica, (2012), 4(1), 352-364.

[4] Megalai, M.S., Ramesh, R. and Maniula, P. Inhibition of Corrosion Mild Steel in Acid Media by Trazodone Drug. Research Desk, (2013), 2(4), 326-333.

[5] Al-Amiery, A.A., Kadhum, A.H., Alobaidy, M.H., Mohamad, B.A. and Hoon, P.S. Novel corrosion inhibitor for mild steel in HCl. Open Access Materials (2014), ISSN 1996-1944, 7, 662-672.

[6] Avwiri, G.O, and Igho, F.O. Inhibitive action of Vernonia amygdalina on the corrosion of Aluminium alloys in acidic media. International Journal Electrochemistry Science, (2001), 2, 549-562.

[7] Uhlig, H.H., Wiley, J. "Corrosion and Corrosion Control” (1985), New York.

[8] Hollingsworth, E.H. and Huniscker, H.Y. "Corrosion of Aluminium and Aluminium alloys" In metals handbook: Corrosion, (1987), 13, 583-609.

[9] Nkiko, M.O. and Bamgbose J.T. Corrosion inhibition of Ocimum Gratissimum extract on ZincAluminium alloy in Hydrochloric acid. Portugaliae Electrochimica Acta, (2011), 29(6), 419427.

[10] Bockris, J.O.M. and Khan, S.U.M. Surface Electrochemistry: A molecular level approach; plenum, (1993): New York.

[11] Eicher, T. and Hauptmann, S. The Chemistry of Heterocycles: Structure, Reactions, Syntheses, and Applications, (2003), $2^{\text {nd }}$ Edition, Wiley-VCH Verlag GmbH, Weinheim.

[12] Popoola, A.P.I and Fayomi, O.S. Environmental failure of $2 \mathrm{M}$ acid strength on zinc electroplated mild steel in the presence of Nicotiana Tobacum, Scientific Research and Essays, (2011), 6(14), 3079-3088.

[13] Fouda, A.S., E-Desoky., Diab, M.A. and Soliman, A.H. Corrosion protection of carbon steel in hydrochloric acid solutions using Heterocyclic compounds. International Journal of Advanced Research, (2014), 2(3), 606-628. 
[14] Halambek, J., Marijana, J., Berkovic, K. and Jasna V. Investigation of novel heterocyclic compounds as inhibitors of $\mathrm{Al}-3 \mathrm{Mg}$ alloy corrosion in hydrochloric acid solutions. International Journal of Electrochemical Science, (2012), 7, 1580-160.

[15] Satapathy A.K., Gunasekaran G., Sahoo S.C., Amit K., Rodrigues P.V. Corrosion inhibition by Justicia gendarussa plant extract in hydrochloric acid solution. Corrosion Science, (2009), 51, 2848.

[16] Solomon, M.M., Umoren, S.A., Udosoro, I.I. and Udoh, A.P. Inhibitive and Adsorption behavior of Carboxymethyl Cellulose on mild steel Corrosion in Sulphuric Acid solution. Corrosion Science, (2010), 52(4), 1317-1325.

[17] Ajanaku, K.O., Ajanaku, C.O., Akinsiku, A.A., Falomo, A., Edobor- Osoh, A. and John, O.M. Eco-friendly impact of Vernonia amygdalina as corrosion inhibitor on Aluminium in Acidic Media. Chemistry Journal, (2012), 2, 4, 153-157.

[18] Noor, E.A. Temperature effects on the corrosion inhibition of mild steel in acidic solutions by aqueous extract of Fenugreek leaves. International Journal Electrochemistry Science, (2007), 3, 996-1017.

\section{AUTHORS' BIOGRAPHY}

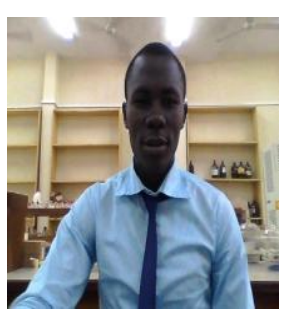

Olanrewaju Aladesuyi, was born in Ojo, Lagos State, Nigeria in 1985. He obtained his Bachelor of Science (Industrial chemistry) from the University of Ado-Ekiti and Master of Science (Chemistry) from Covenant University in 2009 and 2012 respectively. He is currently an Assistant Lecturer in Chemistry department of Covenant University. His research interest includes Corrosion, material chemistry and ceramics.

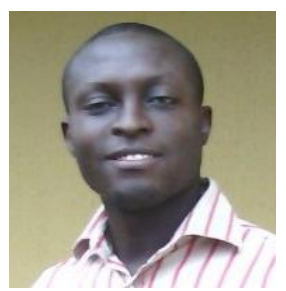

B.O. Fatile, M. Eng. In Metallurgical and Materials Engineering, Federal University of Technology Akure, Nigerian, PGD in Metallurgical and Materials Engineering, Federal University of Technology Akure, HND in Glass and Ceramic Technology at Federal Polytechnic Ado-Ekiti, Nigeria. He is a Lecturer III in the department of Glass and Ceramic Technology, Federal Polytehnic AdoEkiti, Nigeria. His areas of interest include; Development of composite materials, Corrosion Engineering and Ceramic technology.

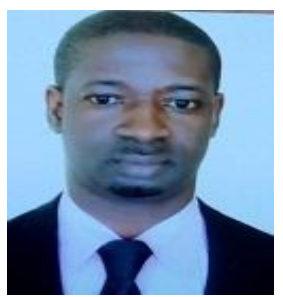

Adedapo, Emmanuel Adebusayo, is from Ilesha, Osun State. He is a graduate of University of Ilorin with B.Sc in Industrial Chemistry and had his M.Sc in Analytical Chemistry at University of Lagos, Lagos. He is currently an Assistant Lecturer in Covenant University. He is presently working on his Ph.D. His research interest is Analytical and Environmental chemistry with a special focus on bioremediation and environmental monitoring.

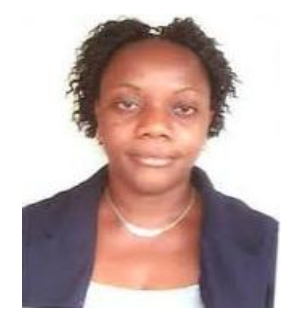

Ajanaku Christiana Oluwatoyin, is an Assistant Lecturer, Covenant University, had her Bachelors degree and Postgraduate Diploma in Education (PGDE), from University of Ibadan $(1992,2004)$ and M.Sc, Covenant University in 2012. A member, Science Teachers Association of Nigeria, (STAN) and member, Chemical Society of Nigeria (CSN). She is in organic/natural product chemistry and currently on a Ph.D programme in Organic Chemistry.

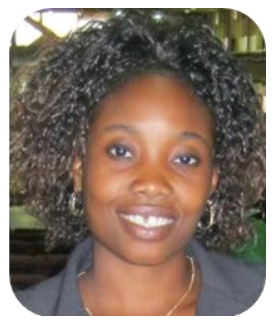

Ifedolapo O. Olanrewaju, was born in Lagos State, Nigeria in 1985. She obtained her Bachelor of Science (Industrial Chemistry) and Master of Science (Chemistry) from Covenant University Ota in the year 2008 and 2012 respectively. She is presently on her Ph.D Thesis at Covenant University. She is currently an Assistant Lecturer in the Department of Chemistry at Covenant University. Research interest is in natural product chemistry. 


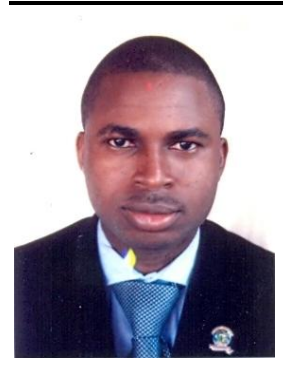

Olayinka O. Ajani was born in Ile-Ife, Osun State, Nigeria. He obtained his Bachelor of Science and Master of Science (Chemistry) from Obafemi Awolowo University, Ile-Ife in 2000 and 2005 respectively. He had his Ph.D at Covenant University under the guidance of Prof. O.B. Familoni. O.O.A. He is a recipient of many outstanding and prestigious awards such as TWAS-CAS PG Fellowship (2009), DAAD Short Research Stay for Scientists Award in Germany, TWAS Research Grant for Individual Scientist among others. He is a lover of Tabletennis.

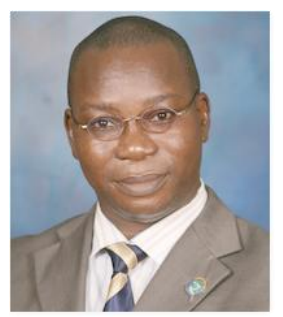

Ajanaku Kolawole Oluseyi, received his B.Sc., M.Sc. and Ph.D degrees in Industrial Chemistry from the University of Ibadan, Ibadan, Nigeria. His research fields cover waste management; food chemistry; corrosion, and CMCs. He has established himself both as an academic and a researcher in Industrial Chemistry for close to twenty years. He is currently teaching/researching at Covenant University. He is a recipient of 2011 CSIR-TWAS Postdoctoral Fellowship Award. He has co-authored quite a number of publications; some of which are published in local and international journals. He is a full professor of Industrial Chemistry with specialization in Materials. 